\title{
OS DESAFIOS DA GESTÃO ESCOLAR DEMOCRÁTICA NA CONTEMPORANEIDADE
}

\author{
BOGEA, Dayse das Dores Silva Ferreira ${ }^{1}$
}

BOGEA, Dayse das Dores Silva Ferreira. Os Desafios da Gestão Escolar Democrática na Contemporaneidade. Revista Científica Multidisciplinar Núcleo do Conhecimento. Edição 02. Ano 02, Vol. 01. pp 664-675, Maio de 2017. ISSN:24480959

\section{RESUMO}

A motivação desse estudo deu-se em virtude de compreender o que pensam os gestores, os docentes e os demais profissionais da educação acerca da gestão democrática na escola. Além do que, entendemos que para esse empreendimento é vital um consenso sobre esse tema, já que a concepção de gestão é complexa na contemporaneidade. Isso porque perpassa vários aspectos que se inter-relacionam, desde a organização estrutural, física da instituição escolar, bem como, outros elementos intervenientes nos processos de ensino e de aprendizagem. Portanto, o objetivo desse artigo científico foi discorrer filosoficamente sobre o tema alvo, a fim de refletir sobre os da gestão escolar na contemporaneidade. Trata-se de revisão de literatura e um convite aos demais pesquisadores dessa área a trazer outros ecos sob essa perspectiva.

Palavras-chave: Gestão Escolar Democrática, Complexidade, Contemporaneidade.

${ }^{1}$ Licenciatura em Matemática - Universidade Estadual do Maranhão - UEMA e Pedagogia - Faculdade do Maranhão - FACAM. Especialista em Gestão, Supervisão e Orientação Educacional - Instituto de Ensino Superior Franciscano - IESF. Inspeção Escolar- Centro Universitário Internacional - UNINTER. 


\section{INTRODUÇÃO}

A motivação desse estudo deu-se em virtude de compreender o que pensam os gestores, os docentes e os demais profissionais da educação acerca da gestão democrática na escola, no Maranhão. Isso porque trabalhamos como professora da educação básica em um município nesse estado e almejamos uma educação de qualidade.

Além do que, entendemos que para esse empreendimento é vital um consenso sobre esse tema, já que a concepção de gestão é complexa na contemporaneidade, pois perpassa vários aspectos que se inter-relacionam, desde a organização estrutural, física da instituição escolar, bem como, outros elementos intervenientes nos processos de ensino e de aprendizagem.

Nessa perspectiva, a construção de um país mais produtivo e de um mundo melhor passa, inevitavelmente, pela garantia do ensino de qualidade para todos. No Brasil, muitos são os desafios a superar para conseguir melhorar a aprendizagem dos alunos. As escolas precisam, por exemplo, ter mais autonomia para decidir sobre as escolhas relacionadas ao seu funcionamento e assumir a responsabilidade pelo cumprimento das metas de aprendizagem, entre outros empreendimentos. Estas decisões por sua vez, precisam ser bem definidas e disseminadas na sociedade.

As avaliações também constituem instrumentos-chave para o desenvolvimento permanente da qualidade da educação, uma vez que se fundamentam em aportes teóricos metodológicos. A maior dificuldade é que, apesar de existirem avaliações nacionais e globais, ainda há pouca compreensão sobre o tipo de resultado que esses exames podem dar. É preciso, portanto, estabelecer sólidos sistemas de avaliação, que sejam capazes de monitorar regularmente o progresso no cumprimento dos parâmetros educacionais. E a disseminação desses resultados pode influenciar na construção de novas políticas públicas e estratégias que podem aperfeiçoar os processos de ensino e de aprendizagem na sala de aula. 
Dessa forma, o caminho da formação contínua e continuada da educação também perpassa pelo fortalecimento do magistério, não tão somente com melhor remuneração, mas também, pelo comprometimento social e político dos docentes e dos demais profissionais da educação diante das comunidades escolares que trabalham.

Diante desse contexto, esse artigo é uma revisão de literatura acerca da gestão escolar brasileira, sendo um recorte da nossa dissertação de mestrado em educação concluído em 2015. Fizemos esse estudo, no intuito de revelar as concepções dos participantes dessa pesquisa no lócus escolhido, na tentativa de compreender os atalhos que tomamos, visando algumas transformações que melhorem a qualidade na educação básica, no estado do Maranhão.

Abordamos, a seguir, a fundamentação teórica desse diálogo filosófico que nos propusemos a realizar como uma revisão de literatura acerca do tema alvo.

\section{O NOVO OLHAR PARA A GESTÃO ESCOLAR}

A abertura dada à Gestão Escolar nunca foi tão notória como se evidência atualmente dentro do âmbito educacional. Ela é um processo pedagógico por excelência, sustentado pelo conhecimento da legislação educacional brasileira, o diagnóstico da realidade escolar para a definição dos objetivos e metas que comporão o planejamento escolar, e, indiscutivelmente, a implantação e consolidação da participação da comunidade escolar nas decisões, buscando soluções e alternativas que viabilizem a melhoria e o funcionamento da escola.

A gestão é nesse aspecto, segundo Libâneo (2008, p. 21) "[...] a atividade pela qual são mobilizados meios e procedimentos para se atingir os objetivos da organização, envolvendo, basicamente, os aspectos gerenciais e técnico-administrativos". Isso significa para a contemporaneidade que se faz necessário um novo olhar para um novo momento da organização escolar, não somente baseado no aspecto administrativo, mas, sim, nos fundamentos da gestão escolar que ora estão envoltos em uma complexidade diante das novas demandas desse milênio. 
Nesse contexto, há uma complexidade de ações assumidas pelo gestor escolar, entre as quais o papel de coordenador geral de atividades da escola, o planejamento, a avaliação, o projeto político pedagógico, sem contar a rotina da escola que envolve todos esses e outros aspectos intervenientes do cotidiano escolar.

Partindo desse pressuposto, definir claramente as atribuições e o papel político do gestor é fundamental. Os escritos sobre gestão escolar propõem uma melhor identificação e compreensão das primeiras concepções em relação às teorias que subsidiaram os alicerces da administração escolar de forma a vislumbrar as transformações e inter-relações diante das práticas educacionais.

Considera-se de grande importância que sejam discutidas algumas premissas acerca da função da gestão escolar, fundamentada na democratização das ações. Destacase a necessidade de revitalizar o papel da escola diante da sociedade e a relação entre elas; de recuperar a escola enquanto local de trabalho global e dinâmico que desenvolve a prática pedagógica voltada para o aprender; de democratizar as relações em todas as suas dimensões; de discutir, rediscutir e avaliar a prática pedagógica sob novas perspectivas; de construir um Projeto Político Pedagógico amplo, coletivo e com definição de parâmetro de qualidade; de criar canais de articulação com a comunidade e outras parcerias; enfim, de rediscutir a organização do trabalho escolar e os mecanismos de garantia da autonomia pedagógica, administrativa e financeira.

Por isso é importante participar do cotidiano da escola. Concordamos com Paro, quando diz:

A democracia e o respeito ao usuário devem estar presentes não apenas nas reuniões do conselho ou na eleição de seus membros, mas em todas as ações e relações da escola, desde as que se dão na situação de ensino, em sala de aula, passando pelo atendimento na secretaria, e atingindo todo o relacionamento que se faz entre servidores, alunos e pais (PARO 2001, p. 83-84). 
Tal ação requer uma integração por autonomia das escolas de forma a garantir o ingresso, a permanência e o sucesso na aprendizagem dos alunos, de maneira que 0 gestor seja um técnico competente e comprometido com seu trabalho.

Especificamente, gestão nos remete a ideia de direção, decisão e deve ser uma atividade mediadora e estruturada na definição e na prática dos objetivos da educação. Então, para que a escola seja de fato eficiente, a gestão é um componente imprescindível e ela deve estar ligada ao aspecto pedagógico e administrativo. Tal desafio nos motivou nesse estudo.

Os ambientes escolares adquirem uma conotação particular, enquanto instituição organizada, uma vez que é dentro delas que se tomam decisões educativas, curriculares e pedagógicas, objetivando a mobilização dos profissionais, autonomia, construção de um projeto sólido e participativo diante de um processo coletivo.

A priori é notório que a escola é vista como uma organização que tem por finalidade desenvolver um conjunto de capacidades de cunho cognitivo, afetivo e até mesmo psicomotor, visando à autonomia intelectual e moral do homem em seus aspectos sociais e civis.

Conforme Luck (2000, p. 47):

A gestão escolar é uma dimensão, um enfoque de atuação, um meio e não um fim em si mesmo, uma vez que o objetivo final da gestão é a aprendizagem efetiva e significativa dos alunos, de modo que, no cotidiano que vivenciam na escola, desenvolvam as competências que a sociedade demanda, dentre as quais se evidenciam: pensar criativamente; analisar informações e proposições diversas, de forma contextualizada; expressar ideias com clareza, tanto oralmente, como por escrito; empregar a aritmética e a estatística para resolver problemas; ser capaz de tomar decisões fundamentadas e resolver conflitos, dentre muitas outras competências necessárias para a prática de cidadania responsável. Portanto, o processo de gestão escolar deve estar voltado para garantir que os alunos sobre o seu mundo e sobre si mesmos em relação a esse mundo, adquiram conhecimentos 
úteis e aprendam a trabalhar com informações de complexidades gradativas e contraditórias da realidade social, econômica, política e cientifica, como condição para o exercício da cidadania responsável.

Portanto, é preciso que se tenham condições para alicerçar os referenciais e os recursos principalmente humanos de forma adequada e competente diante do cenário educacional que a escola é enxergada pelo gestor.

Sendo o gestor a figura central do processo, deve além de ter postura firme e exemplos a serem seguidos, possuir também uma visão de vanguarda, sendo corajoso e encorajador, enfim, ser um pensador com sensibilidade, assumindo seus compromissos firmados. Isso porque a sociedade pós-moderna trás para a escola demandas cada vez mais atuais que oferecem algumas propostas, tais como: a capacidade de trabalhar em equipe, gerenciar ambientes complexos, comunicação eficiente, manejo de tecnologias e uma atualização permanente, entre outras.

\section{CONCEPÇÕES ADMINISTRATIVAS E PEDAGÓGICAS NA GESTÃO ESCOLAR}

Baseado nestas propostas a educação de qualidade requer alteração na concepção e gestão das organizações escolares, onde haja acima de tudo compromisso dos educadores. Segundo Libâneo (2003, p. 55) "[...] o diretor coordena, mobiliza, motiva, lidera, delega aos membros da equipe escolar, conforme suas atribuições específicas, as responsabilidades decorrentes das decisões, acompanha o desenvolvimento das decisões tomadas coletivamente".

Ou ainda, segundo Luck (2000, p.16) "[...] Um gestor da dinâmica social, um mobilizador, um orquestrador de atores, um articulador da diversidade para dar unidade e consciência, na construção do ambiente educacional e promoção segura da formação de seus alunos".

Portanto, a Gestão Escolar é um espaço de articulação das ações desenvolvidas no contexto escolar, cuja responsabilidade alcança as dimensões necessárias a oferecer 
condições adequadas à obtenção dos objetivos estabelecidos coletivamente e construídos a partir do Projeto Político Pedagógico.

Então, no âmbito dos processos de organização e gestão escolar, a Constituição Nacional em seu artigo 208, inciso VII e a LDB no 9.394/96 em seu artigo 15, asseguram à gestão escolar a autonomia nas dimensões administrativa, pedagógica. É importante destacar, que autonomia é sinônimo de responsabilidade individual e coletiva com o envolvimento da comunidade escolar para alcance das metas estabelecidas.

Esses pressupostos servem como objetivo de reflexão em nosso diálogo sobre a gestão escolar, uma vez que é pelas dimensões de gestão que a escola assegura a efetivação das ações pedagógicas, cujos fins estão atrelados à dimensão social de formação do cidadão.

Dessa forma, a discussão das dimensões da gestão escolar nos permite aprofundar o conhecimento acerca do trabalho de organização da escola, focalizando o exercício da autonomia pedagógica em seus diversos conceitos, atribuição de funções, identificação de perfil profissional e suas ações prioritárias.

Nesse sentido, a autonomia da escola remete-se a dimensão pedagógica, no que diz respeito ao conjunto das relações e deliberações sobre o ensino e a pesquisa. É condição necessária para o trabalho de elaboração, desenvolvimento e avaliação do Projeto Político Pedagógico da escola. É também fundamental para a gestão das atividades pedagógico - curriculares.

De acordo com Paro (2001), a gestão pedagógica deve ser compreendida como a liberdade que a escola tem para escolher os conteúdos e os métodos de ensino, sem a qual fica comprometido o caráter pedagógico de sua intervenção escolar.

A forma mais visível que temos para entender a relevância da gestão pedagógica na escola diz respeito à autonomia que ela tem para a elaboração, implementação, avaliação e revisão do Projeto Político Pedagógico, que deve contar com a participação da comunidade escolar e se constitui como ponto relevante para a 
democratização das decisões tomadas pela escola (DUBLANTE, 2011), por meio do compartilhamento de ideias e ações.

As figuras do supervisor pedagógico e, especialmente, a do professor, participam significativamente da gestão pedagógica; ambos são fundamentais para a gestão, cujo trabalho se evidencia na elaboração do plano escolar, realização das atividades curriculares, cumprimento do calendário escolar, e realização de atividades pedagógicas envolvendo as famílias dos alunos, de forma a garantir o alcance dos resultados educacionais, em especial a aprendizagem dos aprendizes.

Já a organização da rotina de trabalho técnico - administrativo, nos remete à dimensão administrativa, como uma prática aliada às ações propostas no projeto político pedagógico da escola, quebrando a velha concepção que distanciava o pedagógico do administrativo.

A gestão administrativa apresenta-se como fundamental apoio ao trabalho docente, buscando oferecer melhores condições físicas e materiais na efetivação das ações pedagógicas. Com um trabalho coletivo, a gestão administrativa emprega diretrizes fundamentadas no regimento escolar, sendo assim, a rotina organizacional da escola outro aspecto considerado importante para atingir os fins propostos no Projeto Político Pedagógico.

Sabe-se que a participação do cidadão e o exercício da cidadania na gestão da escola estão diretamente relacionados a um processo mais amplo de democratização da sociedade. Desse modo, tornar realidade a gestão democrática da escola, como um dos princípios constitucionais, requer a participação de toda a comunidade escolar e de lideranças comprometidas com este novo modo de gerenciar a escola.

Nesse prisma, o processo de construção coletiva pode possibilitar à escola uma reflexão de sua prática cotidiana, comprometendo-o com o processo educativo. Portanto, construir, coletivamente, requer participação e democracia implica em participação. 
Nesse contexto, a gestão enfrenta grandes desafios, pois sua preocupação central são os processos de ensino e de aprendizagem dos alunos diante de uma grande variedade de concepções e crenças docentes na pós-modernidade.

Sendo assim, vários fatores e aspectos intervenientes na gestão escolar influenciam e são influenciados pelos seus gestores e partícipes sendo um processo dialético e complexo.

Abordamos, em seguida, as nuances entre razão e racionalidade apoiadas em Edgar Morin (2008) sendo suas implicações levadas à gestão na escola.

\section{A RAZÃO E A RACIONALIDADE NO CONTEXTO ESCOLAR CONTEMPORÂNEO}

Primeiramente, abordamos as diferenças entre razão e racionalidade buscando na Filosofia pontes de entendimento com a Educação a fim de compreender a sociedade desse milênio e suas novas demandas. Posteriormente, abordamos outras áreas de conhecimento por meio de um diálogo complexo com diversos pesquisadores, no intuito de apreender e compreender o objeto alvo desse estudo.

O conceito de razão é histórico e fundamenta-se na concepção de ciência positivista que a humanidade construiu. Essa concepção advém do paradigma que pressupõe verdades absolutas e a linearidade do pensamento lógico clássico.

Já a racionalidade como afirma Morin (2008) fundamenta-se em outro paradigma. Ela ancora-se na complexidade da sociedade tecnológica e do conhecimento na contemporaneidade.

Nesse sentido, o pensamento complexo que Edgar Morin (2008) enfatiza e possibilita ao entendimento de uma ciência contemporânea que tem em sua genesis inúmeras variantes que se articulam como uma rede de conhecimentos, informações, saberes, entre os elementos. Essa complexidade consiste na articulação entre diferentes aspectos intervenientes que se associam como em uma engrenagem, pois todos são dependentes entre si. E essa multiplicidade equivale a uma totalidade que pode ser 
compreendida à luz de novas abordagens, como por exemplo, ao novo modelo de gestão democrática que entra em cena na escola, na contemporaneidade.

Nesse prisma, por complexo entendemos uma teia interligada e articulada com inúmeras áreas do conhecimento. E, por esse motivo, acreditamos que a racionalidade que vem sendo construída nesse milênio condiz com a educação democrática e de qualidade que almejamos. Isso porque ela pressupõe novos entendimentos, outras soluções aos problemas aparentes no cotidiano escolar.

Isso significa afirmar que uma solução a um problema relacionado à gestão escolar, por exemplo, não pode mais ser explicado e resolvido fundamentado na concepção clássica aristotélica. Isso porque os problemas no "chão" da escola são complexos e exigem um "olhar" multifocal, fundamentado em um prisma de possibilidades. E essa totalidade desse contexto só pode ser vislumbrada diante dessa racionalidade que Morin (2008) menciona em seus estudos, já que diversas demandas se entrecruzam no início do século XXI.

Por isso, estamos em um período de transição de pensamento, saindo de uma concepção clássica de gestão, por exemplo, e indo além, adentrando em outro paradigma, ou seja, um novo modelo de apreender a realidade que nos cerca, isto é, de analisar e compreender a realidade complexa do cotidiano escolar.

Nessa perspectiva, para Morin (2008) é necessário mudar o pensamento para transformar a prática. Dessa forma, concordamos com esse autor e por isso queremos demonstrar nesse capítulo um diálogo profícuo com vários autores de vanguarda acerca do nosso tema alvo.

Passamos a realizar, em seguida, uma breve retrospectiva histórica sobre a Educação no Brasil desde 1996. Dessa forma, pretendemos compreender a totalidade dos aspectos intervenientes que envolvem também essa revisão de literatura acerca do objeto alvo. 


\section{A GESTÃO ESCOLAR NO BRASIL SOB A PERSPECTIVA HISTÓRICA RECENTE}

Nessa perspectiva, com a homologação da Lei n. 9.394/96, definindo as Diretrizes e Bases da Educação Nacional Brasileira e estabelecendo como objetivo geral, tanto para o Ensino Fundamental, como para o Ensino Médio, proporcionar aos educandos a formação necessária ao desenvolvimento de suas potencialidades como elemento de auto realização, preparação para o trabalho e para o exercício da cidadania desenvolveu-se novos rumos a serem trilhados no cenário da Educação Brasileira.

Isso porque a educação no Brasil serviu durante muito tempo, simplesmente, para reproduzir o status quo da sociedade. As chances de frequentar uma universidade eram somente para poucos, ou seja, só conseguia um curso superior que frequentava cursinhos preparatórios para os vestibulares da época.

Quando Hannah Arendt (1997) analisa as dimensões públicas e privadas da modernidade, ela desvela que a escolarização deve propiciar "uma experiência política" inserida na multiplicidade de ideias e nos contraditórios sem os quais mantemos apenas estereótipos e o ser humano é impregnado de criatividade, de diferenças, de pluralismos, de vivências distintas que nos marcam, nos constroem, nos burilam, indistintamente.

Todavia, esse panorama foi se transformando. Com a chegada dos Parâmetros Curriculares Nacionais - PCN's (1998) e novas Diretrizes Curriculares Nacionais (2000) os professores tiveram que mudar sua prática diante de novas expectativas e anseios de um ensino integrado e não mais fragmentado por disciplinas estanques.

Nesse contexto, entra em cena o Exame Nacional do Ensino Médio (Brasil, 2012), que no início tinha como objetivo avaliar a qualidade da educação básica, porém tornouse um "trampolim" para transformar o contexto escolar, inclusive no que diz respeito à gestão democrática escolar. 
Isso porque ele traz consigo a possibilidade de um acesso mais amplo e democrático aos bancos escolares das universidades, e isso pressupõe uma participação maior dos discentes nas salas de aulas.

O aluno não é mais passivo, não aceita mais as "verdades absolutas" do dono da razão que detinha o professor, mas torna-se um protagonista da sua própria história, pois questiona, indaga, participa, ativamente, das dinâmicas da escola, entre outros aspectos intervenientes dos processos de ensino e de aprendizagem. Tal contexto compreende a escola não mais como reprodutora de um saber, mas além de ensinar esse "saber" sistematizado pela humanidade, incentiva novo saberes, outras construções de conhecimentos diversos.

E esse palco traz implicações à gestão escolar nos dias atuais. Além do que, com a Lei n. 9.394/96, a educação básica se constitui nos níveis: fundamental e médio. O currículo manteve uma parte diversificada, a fim de contemplar as peculiaridades locais e a especificidade dos planos dos estabelecimentos de ensino. Aos Estados coube a construção de propostas curriculares, conforme o texto original, que serviriam de base às escolas estaduais, municipais e particulares do sistema de ensino.

Após a promulgação da Lei n. 9.394/96, os Parâmetros Curriculares Nacionais (Brasil, 1998), foram elaborados, em âmbito federal, por um grupo de estudiosos da educação, normatizando o trabalho pedagógico nas diversas áreas do conhecimento. A justificativa oficial dos Parâmetros Curriculares Nacionais fundamentou-se no diagnóstico do alto índice de repetência escolar e evasão, durante as décadas de 1970 e 1980, culpando a escola e o professor pelo trabalho não realizado. A justificativa para os "PCNs" foi tentar construir um consenso, entre os debates e reflexões, em todas as regiões brasileiras numa tentativa de homogeneizar a Educação Brasileira, apesar das diferenças regionais.

Além do que, segundo Diorio (2005) o mundo mudou ao longo do século XX - o capitalismo global ficou mais forte; novos modos de pensar e ser foram adquiridos, apesar de serem contraditórios e desiguais. A mundialização cultural, caracterizada por uma cultura de massa foi intensificada pela mídia e combinada com o marketing 
que difundiu valores e padrões culturais, determinados pela ideologia dominante. E isso implicou em mudanças no cotidiano escolar, onde a gestão democrática tem um papel predominante.

Aos poucos vai se delineando outras condições políticas e de gestão para o envolvimento e a participação da sociedade civil na formação e implementação das ações e programas de universalização da educação básica. O espírito é: todos têm direito a educação, por esse motivo, melhorar os diferentes níveis e modalidades de ensino é tarefa dos poderes públicos.

Nesse sentido, um dos desafios encontrados atualmente no setor educacional é a mudança de ideologia empregada na sociedade, uma atenção da concepção de ensino e do papel da escola enquanto instituição social. Busca-se uma escola democrática, pluralista, que venha valorizar a diversidade frente às problemáticas sociais perpassados pelo educador, educando e os demais gestores e profissionais da educação nesse lócus.

Nessa perspectiva, com o objetivo de melhorar a qualidade da educação brasileira as ações devem se situar, por regulamentação efetiva do regime de colaboração entre a União, Estados, Distrito Federal e Municípios para que, de fato, possam assegurar um padrão de acesso, de permanência e de gestão na educação básica, pautada por políticas e ações que promovam a educação democrática e de qualidade para todos.

\section{A RECONSTRUÇÃO DA DEMOCRACIA NA EDUCAÇÃO}

A construção do processo de democracia no Brasil deu-se início após a década de 80 , fundamentada na Constituição de 1988 , esse mesmo processo tem desafiado a educação de modo que se supere o caráter conservador e proporcione o rompimento da mesma. Fato este que deseja renovar a concepção do sujeito, do mundo e da própria sociedade, de forma que sejam alicerçados em princípios humanos e de democracia.

Segundo Hora (1994, p. 56): 
A administração da educação é entendida como o conjunto de decisões e interesses da vida escolar, no sentido dos processos centralizadores acaba pôr reforçar capitalismo [...], entretanto, o novo panorama de mobilização da sociedade brasileira vem alcançando amplitude nas relações de poder em todas as áreas de ação política no país, [...] os processos se tornam mais abertos e democráticos na sociedade global e estabelece um perfil de democratização em setores específicos em especial na educação. Essa tendência exige que a política educacional e a prática nas escolas assimilem o processo e criem possibilidades para que a manifestação democrática se consolide em cada brasileiro.

O Governo Brasileiro em 1993, desejoso por criar novos modelos de gestão para as escolas públicas brasileiras (autonomia financeira, administrativa e pedagógica), construiu conjuntamente com outros segmentos, o Plano Decenal de Educação para Todos, em virtude de ter ocorrido a Conferência de Educação para Todos em Jontiem nos anos 90 na Tailândia, participaram deste evento 155 países e aproximadamente 1.500 participantes, incluindo-se a este quantitativo, representantes educacionais, entidades governamentais e especialistas em educação, etc.

Segundo Abranches (2003, p. 14) afirma que:

Que esta Conferência analisou os principais pontos da educação mundial e foi um marco importante para a elaboração de novas diretrizes educacionais no mundo, como a lógica de cooperação dos países na administração educacional e a participação de órgãos multilaterais nos serviços educacionais de diversas nações.

Corroborando com essa afirmativa Vieira (2001, p. 63) diz:

A Conferência Mundial de Educação para Todos estabelece um quadro mais amplo para a definição de vários compromissos no âmbito das políticas públicas internacionais, regionais e nacionais para a Educação. Através da Declaração Mundial sobre Educação para todos firma-se o compromisso de satisfazer as necessidades básicas de aprendizagem de todas as crianças, jovens e adultos. 
Finalizada essa conferência todas as entidades ali representadas puderam produzir um documento intitulado "Declaração Mundial sobre Educação para Todos", que em seu bojo traz 10 artigos que representam o consenso e o compromisso de garantir educação para crianças, jovens e adultos. (UNESCO, 1990).

Fica evidente nesses artigos a real necessidade de democratização da escola no que tange primeiramente $\mathrm{o}$ aumento do número de pessoas que devem ter acesso a ela. $\mathrm{E}$ com especial destaque aos artigos aqui abaixo destacados quanto à participação na gestão escolar da sociedade e não somente do Estado. A seguir os artigos (7 e 9):

Art. 7 - As autoridades responsáveis pela Educação em nível nacional, estadual ou municipal têm a obrigação prioritária de proporcionar a educação básica para todos. Não se pode, todavia, esperar que elas supram a totalidade dos requisitos humanos, financeiros e organizacionais necessários a essa tarefa. Novas e crescentes articulações e alianças serão necessárias em todos os níveis [...] Alianças efetivas contribuem significativamente para o planejamento, implementação, administração e avaliação dos programas de educação básica.

Art. 9 - Para que as necessidades básicas de aprendizagem para todos sejam satisfeitas mediante ações de alcance muito mais amplo, será essencial mobilizar atuais e novos recursos financeiros e humanos, políticos, privados ou voluntários. Todos os membros da sociedade têm uma contribuição a dar [...].

Diante da definição das questões prioritárias de caráter global para a educação básica, começou a ser viabilizada várias tentativas de implantar tais propostas em todas as nações, mediante a execução de um plano de inúmeras ações, que supostamente seriam o alicerce dos governos perante a sua nação. Nele está definido que cada governo teria a incumbência de estabelecer suas metas particulares, de acordo com sua perspectiva e prioridades a partir da década de 90 .

No que coube ao Brasil, os representantes a partir dessa Conferência Mundial, elaborou um documento que estabelecia todas as metas para a educação em um período de dez anos (1993-2003). 
Esse documento caracterizava iniciativas que concretizassem os discursos e colocassem no papel propostas de como efetivar experiências educacionais no país em busca da democratização do ensino, da ampliação do acesso a educação [...] (ABRANCHES, 2003, p. 33).

Assim, com a construção desse documento, em 1993, o Governo Federal construiu o Plano Decenal de Educação para Todos. Nele, estavam elencados os mais relevantes compromissos com a educação brasileira para a década. Dessa forma, estados e municípios deveriam elaborar seus próprios planos, com vista a também contemplar as reais necessidades de cada local, tendo cuidado com as características e peculiaridades de sua realidade. Cunha Pinto aponta as principais características desse plano:

[...] equivale a uma agenda mínima da política educacional brasileira, com alguns pontos consensuais: a) professor melhor remunerado e melhor formado; b) elevação do investimento em educação; c) modelo de articulação estado/município; d) sustentação das políticas educacionais; e) qualidade dos serviços educacionais. (CUNHA PINTO, 1995, p. 8).

Do ponto de vista crítico, observamos a concordância das ideias que permearam a Conferência de Jontiem (UNESCO, 1990) e a proposta do plano brasileiro. Onde ambas propunham que a escola deveria ser um espaço educativo mais flexível e, aproximar a comunidade da escola/gestão, tornando-se seus objetivos menos centralizadores. Segue abaixo, trechos que comprovam tal afirmação:

As diferentes clientelas a serem atendidas trazem consigo necessidades de aprendizagem igualmente variadas, exigindo das escolas grande flexibilidade e capacidade da adaptação em seus planos de ensino e métodos de gestão (p. 47).

[...] faz-se necessário uma redefinição das funções, competências e responsabilidades de cada nível da administração educacional, buscando descentralizar e integrar suas ações e possibilitar a gestão articulada dos programas de educação fundamental (p. 46). 
Ficava então estabelecido um paralelo entre o aumento de autonomia e a descentralização dos processos em educação, de forma que as reformas políticas pelas quais o Brasil passava entrassem em consonância com os esperados mecanismos de gestão democrática que começavam a surgir.

Isso posto, fazemos um convite aos demais pesquisadores dessa área que continuem a acrescentar outros ingredientes a esse tema para que o debate filosófico seja cada vez mais profícuo, ressoando outras possibilidades de gestão, no chão da escola, no século XXI.

\section{REFERÊNCIAS}

ABRANCHES, M. Colegiado Escolar - Espaço de participação da comunidade. São Paulo. Ed. Cortez: (2003).

ARENDT, H. Entre o Passado e o Futuro. (Mauro W. Barbosa de Almeida, Trad.) 5a. ed. São Paulo. Editora Perspectiva. (1997).

BRASIL. Constituição da República Federativa do Brasil de 1988. Recuperada de: <http: //www.planalto.gov.br/ccivil03/constitui\%c3A7ao.htm>.

BRASIL. Plano Decenal de Educação Para Todos. Brasília: Ministério da Educação. (1993).

BRASIL. MEC: Lei ㄲo 9.394 de 20 de dezembro de 1996. Brasília: Ministério da Educação.

BRASIL. Secretaria de Educação Fundamental. Parâmetros Curriculares Nacionais: Terceiro e quarto ciclos; Apresentação dos temas transversais. Brasília: MEC/SEF. 1998.

CUNHA PINTO, D. A autonomia da escola. In: Lima, C. T. (Org.). Repensando a Autonomia da Escola. Ed. Laser Press. (1995). 
DIORIO, R. As concepções dos professores e as expectativas dos alunos sobre $o$ Ensino de língua inglesa da $8^{a}$ série do ensino Fundamental. Dissertação (Mestrado em Educação), na Universidade Federal do Ceará, Ceará. (2005).

DUBLANTE, C. A. Gestão Escolar: fundamentos e práticas no contexto das escolas públicas. São Luís: EDUFMA. (2011).

HORA. Dinair Leal de. Gestão Democrática na escola: teoria e prática. Goiânia. Ed. Do Autor. 1994.

LIBÂNEO, J.C. Organização e Gestão Escolar: teoria e prática. 4a. ed. Goiânia: Editora Alternativa. (2003).

, J. C. Organização e Gestão da Escola: teoria e prática. 5a. ed. Revista e ampliada. Goiânia: MF livros. (2008).

LUCK, H. Perspectivas da Gestão Escolar e Implicações quanto à formação de seus gestores. Em aberto, 72 (Gestão Escolar e Formação de Gestores, JUN de 2000, p. 11-34). (2000).

MORIN, E. Ciência com consciência. Rio de Janeiro: Bertrand Brasil. (2008).

PARO, V. H. Implicações do caráter político da educação para a administração da escola pública. Educação e Pesquisa, São Paulo, 8(2): 11-23, jul./dez. (2001).

UNESCO. Organização das Nações Unidas para a Educação, Ciência e Cultura. Declaração Mundial sobre educação para Todos (Conferencia de Jomtien). Tailândia: Unesco, 1990. Recuperado de: <http://www.unesco.org.br/publicação/docinernacionais/>.

VIEIRA, S. L. Políticas internacionais e Educação - Cooperação ou intervenção? In: Dourado, L. F. \& Paro, V. H. (Orgs.). Políticas Públicas e Educação Básica. Xamã: São Paulo, p. 59-90. (2001). 